\title{
Artigo
}

\section{O DIABO E A EDUCAÇÃO}

Este artigo trata da questão do mal, do desejo e suas repercussões no campo educacional. Pensar a educação a partir da psicanálise implica aceitar a falta, a dimensão do inconsciente, o erro, as aberracões, os equívocos e, principalmente, as múltiplas possibilidades de significações. A condição desejante não pode ser universalizada, mas pode ser compreendida. O diabo surge como resistência e desejo, em contraponto a direção do bem e a moralidade silenciadora dos modos de existir. O que propomos nesse trabalho é uma abertura para o exercício do pensar.

Descritores: psicanálise; educação; desejo; diabo.

\section{Primeira martelada}

Quanto mais o campo educacional querer se cientifizar e a pedagogia invocar um estatuto de ciência, mais estarão expressando um interesse em não pensar. Che Vuoi? O que quer a Educação? Não pensar! O que significa dizer que o desejo da Educação é não pensar. Não pensar sobre o quê? Sobre o impensado. Dito de outra maneira, O que quer a Educação? Quer devorar! A Educação precisa devorar a tudo e a todos porque faz parte de seu movimento infindável de repetição, o trabalho de Sísifo, a tentativa de tamponar a sua falta que resulta de sua constituição metafísica. Só há um remédio para a doença da Educação: a sua desaparição. Semelhante ao desaparecimento de uma assombração.

A Educação ocupa o lugar do demônio, o lugar de Belzebu, o fantasma horripilante, a esfinge, a miragem metafísica. O Demônio é metafísico, assim como Deus. Por isso a Educação transita facilmente entre Deus e o Demônio, entre a redenção e a rejei-

Doutorando em Psicologia Clínica da Pontifícia Universidade Católica de São Paulo - PUC/SP e Professor Assistente da Universidade Estadual de Santa Cruz - UESC, Ilhéus-BA. 
ção. Nesse sentido, podemos fazer a ilação entre o movimento da aceitação e da repulsa. Entre o acolher, a errância e punir os que não alcançam suas metas. A Educação se apresenta, então, nesse eterno jogo de oscilar entre ser a "Biondetta" ou Belzebu, a Biondetta-Belzebu. Essa história está presente no romance O Diabo Amoroso, de Jacques Cazotte (1719-1792) ${ }^{1}$. Cito-o a partir do próprio Cazotte (Leite, 1991), de Gustavo Etkin (1996), Márcio Leite (1991) e Jimenez e Motta (1999).

\section{Segunda martelada}

A história se passa resumidamente da seguinte maneira: "Soberano" (o mais velho do grupo, que na nossa interpretação poderia ser o professor), um personagem da história, leva Álvaro (o protagonista, rapaz jovem, que pode ser visto, como o aprendiz, o aluno) e outros colegas até as ruínas de um templo pagão, lugar sombrio e silencioso, a fim de conhecerem o Diabo. Lá, Soberano fez um círculo no chão (o "círculo mágico" de proteção, do qual não poderia sair para não ser pego pelo demônio) "e o preencheu com alguns caracteres. Forneceu-se então, a Álvaro, uma fórmula mágica pela qual se evocaria Belzebu. $\mathrm{O}$ que, de fato, imediatamente aconteceu" (Leite, 1991, p. 51). Apareceu o diabo com uma cara horrível, no formato de uma cabeça de camelo e lhe responde ${ }^{2}$, com uma voz estridente: Che Vuoi? (que queres?). Álvaro se apavora e pergunta por que ele se apresenta "sob essa forma repugnante". O Diabo lhe faz lembrar que ele o chamou. Respondendo ao desejo do protagonista, que lhe ordena mudar de forma, o camelo se transforma em uma cachorrinha, depois em uma cantora e depois em uma bela, sensual e angelical ninfeta à sua disposição, a "Biondetta", que passa a realizar todos os seus desejos. Imediatamente, as ruínas se transformam em um castelo. Qualquer desejo pode ser realizado por Belzebu.

O romance será marcado por essa dúvida atroz do protagonista se "Biondetta" é ou não é o Diabo. Como aponta Leite (1991), essa hesitação "poderia ser entendida como uma estratégia do desejo”. (p. 54). Esta dúvida percorre a Educação em sua ambiguidade de se apresentar ora na condição de Deus, que salva e redime, ora na condição do Diabo, que castiga e aniquila.

Álvaro não resiste e cede aos desejos de "Biondetta" de transar com ele. Agora ela lhe pergunta se ele a ama e pede a seu amor que diga a "seguinte frase: "Eu te amo, Belzebu" (Etkin, 1996, p. 113). Nesse momento, ela aparece novamente com a cara de camelo, aquela cara terrível que lhe pergunta: “Che Vuoi?” (Etkin, 1996, p. 113). A resposta de Álvaro é renunciar "ao desejo por essa mulherdiabo" (Leite, 1991, p. 55). Na interpretação de Leite (p. 58), no conto há 
uma dualidade entre o saber (representado por Soberano, que ocupa um lugar de mestre, do que sabe, o que significa "ser soberano dos seus próprios desejos") e o desejo (representado por Biondetta), no qual um sempre exclui o outro, que poderia ser traduzido pela "disputa entre o desejo e a razão". Assim, é possível para Leite (p. 19) pensar que "no século XVIII, o diabo, mais que representação do mal, tornou-se o representante do poder. Poder que seria poder saber. Saber o que não se pode saber, saber sobre a Luz roubada aos céus da qual Lúcifer é seu portador". É neste momento também que começa uma liberdade que antes não existia a "de se poder pensar o mal como necessário para a existência do bem" (p. 64). No campo educacional, a questão do mal fica subsumida de maneira parecida à época do primórdio da verdade divina, do conhecimento emanado de deus na Idade Média, onde existiria um possível império da significação única.

No entender de Leite (1991), o diabo seria um "efeito da radicalização do dualismo cristão, não existia dessa forma nas civilizações anteriores, mas produziu uma influência fundamental no pensamento ocidental, desde os primórdios do cristianismo até os dias de hoje". O diabo para esse autor "funcionaria como um condensador de valores, que atribuiria significação moral aos mais variados seres" (p. 63).

Dentro desse quadro de liberdade advindo com o Iluminismo, tornando relativos os posicionamentos morais tanto em relação ao Bem como em relação ao Mal, surge o poeta inglês William Blake, que "poderia dizer, sem temor de ser queimado na fogueira, que o Bem é a passividade que obedece à Razão, e o Mal a atividade que nasce da energia" (p. 19). O medo ao Diabo foi paulatinamente sendo desfeito, à medida que o conhecimento iluminista foi se expandido e o homem se esclarecendo e se educando institucionalmente.

Também na versão de Leite (1991, p. 73), encontramos um paralelo entre a história de Cazotte e o Fausto de Goethe (17491832). O que nos interessa observar da história do escritor alemão, na interpretação de Marshall Berman ${ }^{3}$, é o fato de Fausto desejar para si "o conhecimento que incluiria todo tipo de experiências humanas, acumulando-as num interminável processo de crescimento interior", uma espécie de "autodesenvolvimento a partir das 'forças ocultas", que o diabo representaria. Desconfiamos, como exercício de pensamento, do privilégio de uma significação do bem sobre o 


\section{Artigo}

mal. A partir dessa desconfiança, o estranhamento de pensar a questão do mal na educação pode ampliar - como contraponto - a potência das narrativas educacionais. Abertura parecida ao que ocorre no campo literário.

A Educação ocupa esse lugar que se assemelha ao de Belzebu. A Educação pode dizer: Você quer conhecer? Quer educar-se, ser um sujeito emancipado, autêntico, "consciente de seus pensamentos e responsável pelos seus atos"? (Ghiraldelli Jr, 2000, p. 23-24) Como no projeto da educação moderna. Então venha: Eu te quero! Repita comigo: "Eu te amo, Belzebu”. Poderíamos pensar, então, em uma possessão educacional, metafísica, do sujeito.

\section{Martelada infernal}

A questão de se pensar o Diabo tem a ver, como propõe Corazza (2002a), com a temática da desaparição do sujeito, da crítica à filosofia do sujeito. Porque se com Nietzsche Deus foi morto e com sua morte o projeto do sujeito ontológico, epistemológico, autônomo, esclarecido, absoluto e moral também se esvai, seria então o Diabo que lhe daria alguma sustentação? Seria, então, o Diabo um sucessor de Deus? Ou seria outra Individualidade? "Se for um sucedâneo, entra na mesma crítica da subjetividade. Mas se for outra coisa, se Deus está morto, mas o Diabo não estiver?" 
(p. 22). A educação moderna se estrutura a partir da noção de sujeito (Ghiraldelli Jr, 2000). A pergunta fundamental que Corazza faz é de que "se Deus não mais ampara a ideia de sujeito, o Diabo ampara?”, ou seja, se Deus não sustenta mais o sujeito, "o Diabo como Ser do Mal Radical" é quem ainda fornece algum apoio? $\mathrm{Ou}$ o sujeito realmente acabou, seja do lado de Deus, seja do lado do Diabo?" (p. 22).

Essa a questão é uma derivada, um ataque ao conceito de sujeito inventado na modernidade que permanece atrelado a Educação até hoje. Podemos ver um "desconhecimento" no campo educacional sobre os debates existentes em outros campos do saber, como na literatura e na filosofia, de toda uma tradição que trata da desconstrução e desaparição do conceito de sujeito moderno. Observamos isso, em vários discursos pedagógicos que ainda pregam ser o objetivo da educação o de "formar sujeitos críticos e conscientes". Chamamos a atenção que na educação não se quer e se resiste perceber, para que permaneça invisível, a Educação com "E" maiúsculo, essa metanarrativa que nos assombra.

A pertinência das inquietações de Corazza (2002a) levanta questões que mexem com a estrutura dogmática educacional, onde caberia indagar se "Toda santidade e todo mal são necessariamente religiosos? Ou se há outros santos e outros diabos", como por exemplo, nas Teorias Pedagógicas? (p. 25).
Em vários momentos do constrangimento educacional, ocorre a situação de amedrontamento que a história da Biondetta e Belzebu mostra. Basta ver a condução de certas disciplinas, que pode caminhar bem até chegar o momento da Prova, na qual mostra a sua cara de camelo, ou mesmo pode o assombramento ter a sua data marcada pelo aulista, em que os alunos que não se comportam bem, no dia da Prova, têm seu acerto de contas com o (a) Coisa-Ruim. O dia do Exame, incluído aí o dia de uma defesa de monografia, dissertação ou tese, ou mesmo as provas de um concurso, são marcados como momentos diabólicos, em que a Educação mostra a sua terrível e horripilante cara de camelo, sua cara de Belzebu.

Dizer, por exemplo, que o dia da prova é o dia do encontro com o (a) "Coisa Ruim", significa nomear uma angústia produzida pelo processo de exame que não deveria ocorrer. Esse é o tipo de excesso que a educação traz, e que não deveria trazer. Entendo que no processo de educação não deveria existir nem sofrimento, nem angústia. Uma avaliação não pode se prestar para despertar angústia, aflição, medo e sentimento de incapacidade no estudante, isso nada ter haver com educação e sim com sadismo. Não é a toa que dizemos que a avaliação, no caso o exame, ser é um encontro com o Belzebu. Essa avaliação horripilante é a que angustia, deprecia, é a que pode ser um acerto de contas ou um exercício de sadis- 


\section{Artigo}

mo do docente. O sofrimento é algo absolutamente desnecessário e não deve está presente em lugar algum, muito menos no processo educacional. Essa ideia de sofrer para alcançar a redenção, ou como efeito colateral da educação, nada mais é que a estupidez esculpida. Uma ideia religiosa cristã, do sofrimento como meio de alcançar uma condição espiritual superior.

Corazza (2002a, p. 12) diz que: "o inferno atravessa o mundo da Educação" podendo "aterrorizar seu pensamento" e convida "o pensamento educacional a pensar o inferno, a torná-lo o seu ponto de alucinação". (p. 12) A proposta é escapar de uma bondade essencial que possa orientar o trabalho do docente, inclusive, a própria visão de uma acesse educacional, de melhoria do homem, de redenção.

As convicções de Verdade presentes em ações e discursos educacionais sofrem um ataque mortal ao se deparar com o mal, o obscuro, o infernal, que lhe remete a um pensar não planificado, incorporando a desmesura, a morte e as iatrogenias como parte da educação. Uma educação que não visa tornar "sujeitos críticos e conscientes", porque simplesmente não existe nenhum sujeito, só há uma possibilidade, um fluxo, uma ambiguidade falante, um ponto sem sentido e assustado que precisa se inventar e inventariar significações a todo instante. Essa diferença de postura, a partir também do inferno, pode ser 
decisiva para se pensar a educação como um construir de caminhos e não de percorrer ou se adaptar a um caminho. Filosoficamente falando, pensamos uma educação para a morte e não para atingir os céus.

\section{Desejo, diabo e educação}

A associação entre a história de Cazotte e a Educação faz sentido especialmente quando consideramos o ponto de vista explorado por Leite (1991, pp. 55-56) de que toda a trama do conto "funciona no sentido de explorar esse desejo de saber [...] Qual seria a natureza desse desejo de saber, e o que ele implicaria?"4. A Educação acena com a promessa de um saber que é terrível para o estudante. Nós não queremos absolutamente saber, fugimos do saber por meio do conhecer, porque o saber significa se dar conta da falta, da impossibilidade do saber, de abandonar a ideia de uma significação completa frente à falta de significação e de sentido. Ao perguntarmos ao estudante "Che Vuoi? O que você quer?”, ele responderá: "não saber".

A pergunta que nos move no conhecer do ponto de vista da psicanálise nada tem a ver com a filosofia, nem com um amor à sabedoria, ou ontologia; a pergunta principal e irrespondível é: por que há dois sexos? Por que há o outro sexo ${ }^{5}$ ? Essa oposição, que nos coloca em uma posição de desejo e de demanda, nos mostra a impossibilidade de saber sobre o outro sexo, sobre o gozo do outro sexo.

Neste caso, o diabo não é somente o porta-voz do desejo (como pode ser compreendido em termos psicanalíticos), é também a assombração, o terror de impedir a condição desejante no campo educacional e manifesta-se na inadequação entre o significante educacional imposto e o escolhido. É o demônio e seus desdobramentos, seu duplo, e não uma oposição Deus X Diabo.

Poderíamos perguntar quais seriam os limites do desejo do campo educacional; seria por acaso o desejo de um único desejo? Que desejo seria este que a Educação propaga que nos faz perder ou alienar os desejos? Considerando, como ponto de partida, as investigações de Leite (p. 16), que constatou que foi na Idade Média "a época do império da Igreja sobre os desejos dos homens" que se 
reduziu todos os seus desejos a um único, que seria o "desejo de Deus", seria possível pensar que a escola substitui a Igreja nessa tarefa de nos impor um desejo único? Haveria, portanto, na história da Educação, um império sobre os desejos dos homens? Se há, que desejo único seria este?

Há uma coincidência entre a queda da Igreja na versão de promotora da ordem do Ocidente medieval e o surgimento e ascensão da escola, que passará a ocupar este lugar, que paulatinamente lhe foi passado pelo clero católico. Não foi à toa que o casamento entre Igreja e Escola foi tão bem sucedido. A escola sucedeu, guiada pela própria Igreja, a tarefa de comandar o seu Império dos desejos sobre os homens, o que passaria a acontecer de forma mais elaborada, dissimulada e eficiente, como ainda ocorre até hoje.

Não importa se laica ou não, a educação é estruturada pelo disciplinamento e a obediência em qualquer cultura e tem sempre em mente uma convicção de melhoria do homem, um homem-desejo, que nasceria defeituoso, pelo Pecado Original. No que concerne "ao livre exercício do desejo" (Leite, 1991, p. 65), o campo educacional não se encontra na modernidade, mas na Idade Média. Sobre esses pontos, poder-se-ia supor como faz Corazza (2002a) que "pensar a Educação por meio de uma filosofia do inferno desvincula a moral pedagógica da religião cristã? Descristianiza o pensamento educacional? Desenraizao da fé moralizadora?" (p. 24).

Fustigar a Educação com o tridente afiado do diabo ou de seu martelo encantado, pode, no nosso entendimento, contribuir para potencializar o pensamento educacional. Corazza (2002a, p. 24) coloca uma interrogação nessa perspectiva, se efetivamente a filosofia do inferno "afasta os seus praticantes de serem culpados, endividados, filiados, condenados, cristãos? É uma estratégia ativa, que vivifica e potencializa o pensamento da Educação? Ou, ao contrário, confirma totalmente o ódio à vida e o moralismo de São Paulo?” (p. 24). Está em jogo certo primado da significação única incrustado na educação. A multiplicidade de significações implica na construção, customização e invenção de múltiplos estilos, na renúncia da alienação e na convivência entre diversos desejos. Ao subsumirmos o mal e a ambiguidade no pensar educacional, adotamos certa postura moral higienizadora que busca a beatitude, a docilidade e a conformidade.

Interpretando Lacan, Leite (1991) aponta que "o desconhecimento em que o homem permanece em relação a seu desejo é menos desconhecimento do Outro que ele demanda do que desconhecimento de onde ele deseja" (p. 155). Essa perspectiva, em termos lacanianos, significa que "o inconsciente é o discurso do Outro", "o desejo do homem é o desejo do outro", que se resume "que é como outro que o homem deseja". 
Em termos psicanalíticos, nos defrontamos com "uma alienação fundamental do homem frente à ignorância dos seus próprios desejos, que o coloca numa condição de condenado, a desejar muitas vezes o que não quer, ou a querer o que não deseja" (p. 155). Essa alienação ocorre, em suas palavras, "não sem antes guardar uma opacidade subjetiva que o distancia da necessidade. Opacidade que, para Lacan, faz a real substância do desejo" (p. 155). Daí a pergunta dirigida ao Outro: Che vnoi? (que queres de mim?).

A Educação exerce uma atração por ser um campo de gozo. O campo educacional é um campo de gozo. Em psicanálise, gozo significa a satisfação na insatisfação. O que quer dizer que na trajetória educacional temos uma permanente satisfação na insatisfação. A promessa de um saber que não pode ser alcançado e a promessa de realização de desejo que não pode ser permitida. Dessa maneira, se realiza o controle e a docilização dos corpos que não se resumem apenas a questão do disciplinamento, mais se ampliam para o controle do desejo. É o controle do desejo que interessa ao campo educacional e não a multiplicidade de saberes e a proliferação de conbecimentos.

\section{Martelada de misericórdia}

A História da Educação, assim como a História da Filosofia, não se- 
ria somente como Heidegger pensou "a história do esquecimento do ser", mas seria também a história do esquecimento, do ocultamento da falta. O que nos permite dizer que "a variação dos discursos, como tentativa de evitar a falta no Outro e, portanto, a angústia, seria a estrutura mesma da história das mentalidades" (Leite, 1991, p. 166); ou seja, a tentativa de produzir um Outro completo, como seria o caso do deus da religião (p. 158); na interpretação de Leite (1991), a própria "história das religiões seria a história das maneiras como os homens inventaram Outros sem falta" (p. 158).

$\mathrm{Na}$ inventividade de uma filosofia do inferno na Educação, Corazza (2002a, pp. 31-32, grifos nossos) propõe pensar a Educação com três características de pensamento, que funcionariam como uma "máquina de guerra para combater os aparelhos que capturam o pensamento educacional", que seriam: "através de conceitos infernais", de "traçar a infersfera" (que significa a "casa do conceito infernal", o "plano deserto, que os conceitos infernais povoam sem partilhar, nem dividir") e de "ter um estilo infernal da diferença". Essa máquina teria a função de "promover a desterritorialização do pensamento da Educação, fazê-lo ingressar na criação de uma nova educação por vir". Poderia ser essa máquina - uma máquina autopoiese de produção que se inventa no seu acontecer (Corazza, 2002a, p. 16). Criar estilos (Tadeu, 2004) e estilísticas próprias, Customizar, Poetar, Errar... seria talvez algo como também propõe Corazza de "diagnosticar os devires-acontecimentos da Educação, que apelam a formas futuras, resistem ao presente e invocam uma nova raça de educadores: bastarda, anárquica, nômade, demoníaca" (p. 32, grifo nosso).

Esse jogo, do qual trata nossa pensadora da educação, nos remete a um posicionamento abissal o de que "filosofar o inferno é experimentar uma experiência do pensamento que se faz no território da Educação" e pode também "ser definido como uma teoria das multiplicidades" (pp. 32-33). Talvez isso possa significar a possibilidade de pensarmos o avesso educacional, a inversão e revirada da educação. Pode implicar em pensar a educação como uma literatura especifica e não como ciência. A educação como "fábrica de narrativas", como propõem o filósofo Paulo Ghiraldelli Jr. (2000, p. 85-86), que seria "a atividade de redescrever todas as relações que envolvem o ensino: desde a relação professor-aluno até a da política educacional passando por aquelas relações pressupostas pelos métodos pedagógicos etc.". 
Corazza (p. 35), na sua "Artefatura do infernal", diz que "pensar desse modo é experimentar tudo o que é estranho e problemático no pensamento educacional, tudo o que, até agora, foi banido pela moral, ressentimento, má consciência, niilismo cristão, fé no ideal".

Sabemos, por outro lado, como nos alerta a própria Corazza (p. 36), que "pensar o inferno na Educação é um exercício perigoso", porque o seu plano é o de "seguir a linha de fuga do vôo da bruxa, do passeio do vampiro, do andar sem rumo do centauro, do vagar infinito de todas as individualidades estranhas que povoam o Mundo-Verdade da Educação" (p. 36). Baseado nesse entendimento, as consequências desse pensar perigoso, gerarão resistências e reprovações instintivas na opinião educacional. A radicalidade desse pensamento, que provoca reações imunológicas, é o de não perguntar "se os conceitos que cria, o plano que traça, os personagens que inventa são feios ou bonitos, falsos ou verdadeiros. Mas se tudo que está sendo criado tem vida, tem existência, dá algo a pensar, aumenta e exagera o pensamento a partir de sua face atual" (p. 35, grifo nosso).

Para dar conta de novas significações, inventando caminhos e abrindo picadas, corremos o risco da maldição, da deserção, de sermos um Estranho no Ninho. Podendo cair na exclusão social, intelectual ou afetiva. A possibilidade que Corazza (2002a) levanta da tarefa específica dessa for- 


\title{
Artigo
}

mação infernal é de "ser capaz de pensar o impensável, o intratável, o impossível, o não-pensado do pensamento educacional. Embaralhar a sintaxe e organizar o pensamento numa lógica às avessas, constituindo-se como um pensamento-outro da Educação" (p. 31, grifo nosso). Essa postura filosófica permite conceber, na nossa invenção, o professor como um pensador e não como transmissor, repassador ou intermediador de conhecimentos. Sendo seu trabalho, caudatário de Nietzsche-Deleuze, o de criar, roubar e manipular conceitos.

A partir dessa perspectiva filosófica, Corazza (2002b) explica que este tipo de pensamento Liberta-se "do culto à totalidade, transcendência, dialética, metafísica, humanismo, bem como dos casais de tensões certo/errado, culpa/castigo, bem/mal, morte/vida. Foge do pensamento único para tornar as singularidades possiveis, afirmar o múltiplo, multiplicar os devires" (p. 31). Outros desdobramentos importantes, rumo a essas múltiplas formas de pensar, são as considerações do inconsciente e do equívoco. Uma educação que contemple o equívoco e a dimensão do inconsciente, reconhecendo a existência de uma falta impossível de tamponar. Tomado por esses pensamentos, surge uma educação inquietante, nervosa, incompleta, impossível, na qual múltiplas significações podem emergir e certezas e Verdades decair, em um exercício interminável.

THE DEVIL AND EDUCATION

\begin{abstract}
This article deals with the problem of evil and desire, and their repercussions en the area of education. Thinking about education by way of a psychoanalytical base implies acceptance of one's lack, one's unconsciousness, and ones errors, aberrations, mistakes and principally one's multiple possibilities of meaning with respect to the signs in one's environment. The condition of desire cannot be universalized, but it can be understood. The devil appears, as resistance and desire, as counterpoint toward good and the moral silencer of means of existence. We propose an opening of thought and dialogue along these lines.
\end{abstract}

Index terms: psychoanalysis; education; desire; devil. 


\section{EL DIABLO Y LA EDUCACIÓN}

\section{RESUMEN}

Este articulo se trata del problema del mal y del deseo y sus repercusiones en el campo educacional. Pensar en la educación desde la base de la psicoanálisis implica aceptación de lo que le falta a uno, la dimensión de la inconsciencia de uno, y sus errores, aberraciones, equivocaciones y principalmente las múltiples posibilidades de significación con respecto a los signos en sus alrededores. La condición del deseo no puede ser universalizada, pero puede ser comprendida. Surge el diablo como resistencia y deseo, contrapunteando en la dirección del bien y la moralidad silenciadora de los modos de existir. Lo que proponemos en este trabajo, entonces, es una abertura para ejercitar el pensamiento.

Palavras clave: psicoanálisis; educación; deseo; diablo.

\section{REFERÊNCIAS}

Corazza, S. M. (2002a). Para uma filosofia do inferno na Educação: Nietzssche, Deleuze e outros malditos afins. Belo Horizonte: Autêntica.

Corazza, S. M. (2002b). O que quer um currículo?: pesquisas pós-críticas em Educação (2. ed.). Petrópolis, RJ: Vozes.

Etkin, G. E. (1996). Uma introdução a Lacan: o real e a metáfora paterna. Salvador, BA: Máthesis.

Ghiraldelli Jr., P. (2000). O que é filosofia da educação: uma discussão metafilosófica. In Ghiraldelli Jr., Paulo (Org.), O que é Filosofia da Educação? (pp. 7-88). Rio de Janeiro: DP\&A.

Jimenez, S., Motta, M. B. (Org.). (1999). Considerações psicanalíticas sobre o tema do diabo. In $O$ desejo e o diabo: as formações do inconsciente em Freud e Lacan (pp. 15-23). Rio de Janeiro: Contra Capa.

Leite, M. P. de S. (1991). O Deus odioso: psicanálise e representação do mal In J. Cazotte. O diabo amoroso (Camilo Castelo Branco, trad.). São Paulo: Escuta. (Título original: Le diable amoureux).

Tadeu, T. (2004). A Golpes de estilo. In A. F. B. Moreira, J. A. Pacheco, \& R. L. Garcia (Orgs.), Currículo: pensar, sentir e diferir (pp. 215-223). Rio de Janeiro: DP\&A. 


\section{Artigo}

\section{NOTAS}

1 Escritor, político e místico francês do Século XVIII. Sobre Cazotte, ver Leite (1991).

2 É interessante notar que Cazotte (1991, p. 180) diz que o Diabo lhe responde e não que lhe pergunta como deveria ser. $\mathrm{O}$ que significa dizer que a resposta parte do próprio Álvaro, que a inverte na segunda pessoa, transformando uma pergunta em resposta, por se tratar, em termos psicanalíticos, de uma indagação sobre o desejo que não pode ser feita diretamente na primeira pessoa, como observou Jimenez (1999, p. 18): “quando o sujeito se pergunta por seu desejo, tende a usar a segunda pessoa. Em vez de perguntar o "que quero?", ele diz, "que queres?"

3 Autor de Tudo que é sólido se desmancha no $a r$, no qual desenvolve um novo enfoque sobre Fausto (Leite, 1991, p. 72).

4 Este saber está ligado, segundo Leite (1991, pp. 55-56), a partir de Milner, a "um saber mágico, que quer dizer um saber que reduziria o intervalo entre o desejo e a sua realização".

5 Devo os préstimos desse entendimento ao psicanalista Jairo Gerbase, do Campo Lacaniano, Salvador-BA.

geraldoreimao@yahoo.com.br

Recebido em agosto/ 2010. Aceito em abril/ 2011. 